\title{
Erratum to: Development of a Unifying Target and Consensus Indicators for Global Surgical Systems Strengthening: Proposed by the Global Alliance for Surgery, Obstetric, Trauma, and Anaesthesia Care (The G4 Alliance)
}

\author{
Adil Haider ${ }^{1,2} \cdot$ John W. Scott ${ }^{1,2} \cdot$ Colin D. Gause ${ }^{3} \cdot$ Mira Meheš $^{4} \cdot$ Grace Hsiung $^{3}$ • \\ Albulena Prelvukaj ${ }^{4} \cdot$ Dana Yanocha $^{4} \cdot$ Lauren M. Baumann $^{3} \cdot$ Faheem Ahmed $^{5}$. \\ Na'eem Ahmed $^{5} \cdot$ Sara Anderson $^{6} \cdot$ Herve Angate $^{7} \cdot$ Lisa Arfaa $^{4} \cdot$ Horacio Asbun ${ }^{8,9}$. \\ Tigistu Ashengo ${ }^{10,11} \cdot$ Kisembo Asuman $^{12} \cdot$ Ruben Ayala $^{13} \cdot$ Stephen Bickler $^{14} \cdot$ Saul Billingsley $^{15}$. \\ Peter Bird ${ }^{16} \cdot$ Matthijs Botman $^{17} \cdot$ Marilyn Butler $^{18} \cdot$ Jo Buyske $^{19} \cdot$ Angelo Capozzi $^{20}$ • \\ Kathleen Casey $^{4}$ - Charles Clayton ${ }^{21} \cdot$ James Cobey $^{4,22} \cdot$ Michael Cotton $^{23} \cdot$ Dan Deckelbaum $^{24,25}$. \\ Miliard Derbew ${ }^{26}$ - Catherine deVries $^{27} \cdot$ Jeanne Dillner $^{28} \cdot$ Max Downham $^{29} \cdot$ Natalie Draisin $^{15}$. \\ David Echinard $^{30} \cdot$ Sohier Elneil $^{31}$ - Ahmed ElSayed ${ }^{32}$ - Abigail Estelle $^{33} \cdot$ Allen Finley $^{34}$. \\ Erica Frenkel $^{35}$ • Philip K. Frykman ${ }^{36}$ - Florin Gheorghe ${ }^{37}$ • Julian Gore-Booth ${ }^{38}$. \\ Richard Henker ${ }^{39} \cdot$ Jaymie Henry $^{4}$ - Orion Henry ${ }^{40}$ - Laura Hoemeke ${ }^{41}$ - David Hoffman ${ }^{42}$. \\ Iko Ibanga $^{43}$ - Eric V. Jackson Jr. ${ }^{44}$ • Pankaj Jani ${ }^{26}$ • Walter Johnson ${ }^{45}$ • Andrew Jones ${ }^{46}$ • \\ Zeina Kassem $^{47}$ - Asuman Kisembo ${ }^{12}$ - Abbey Kocan ${ }^{48}$ - Sanjay Krishnaswami ${ }^{49,50}$. \\ Robert Lane ${ }^{51}$ - Asad Latif ${ }^{52}$ - Barbara Levy ${ }^{53}$ - Dimitrios Linos ${ }^{54,55} \cdot$ Peter Linz $^{56}$. \\ Louis A. Listwa ${ }^{57}$ - Declan Magee ${ }^{58} \cdot$ Emmanuel Makasa $^{59} \cdot$ Michael L. Marin $^{60}$. \\ Claude Martin $^{61} \cdot$ Kelly McQueen $^{62} \cdot$ Jamie Morgan $^{63} \cdot$ Richard Moser $^{64} \cdot$ Robert Neighbor $^{65}$. \\ William M. Novick ${ }^{66,67} \cdot$ Stephen Ogendo $^{26} \cdot$ Akinyinka Omigbodun $^{68} \cdot$ Bisola Onajin-Obembe $^{69}$. $^{6}$ \\ Neil Parsan ${ }^{70}$ - Beverly K. Philip ${ }^{71} \cdot$ Raymond Price $^{27} \cdot$ Shahnawaz Rasheed $^{72}$ - Marjorie Ratel $^{73}$. \\ Cheri Reynolds $^{74} \cdot$ Steven M. Roser ${ }^{75} \cdot$ Jackie Rowles $^{76} \cdot$ Lubna Samad $^{77} \cdot$ John Sampson $^{78}$. \\ Harshadkumar Sanghvi ${ }^{11}$ - Marchelle L. Sellers ${ }^{79}$. David Sigalet ${ }^{80}$ • Bruce C. Steffes $^{81}$. \\ Erin Stieber $^{82} \cdot$ Mamta Swaroop $^{83} \cdot$ John Tarpley $^{62} \cdot$ Asha Varghese $^{84} \cdot$ Julie $_{\text {Varughese }^{85}}$. $^{\text {. }}$ \\ Richard Wagner $^{86} \cdot$ Benjamin Warf $^{87} \cdot$ Neil Wetzig $^{88} \cdot$ Susan Williamson $^{89} \cdot$ Joshua Wood $^{90}$. \\ Anne Zeidan ${ }^{91} \cdot$ Lewis Zirkle $^{28} \cdot$ Brendan Allen $^{4} \cdot$ Fizan Abdullah $^{3,4}$
}

Published online: 22 June 2017

(C) Société Internationale de Chirurgie 2017

\section{Erratum to: World J Surg DOI 10.1007/s00268-017-4028-1}

In the original version of this article, Dan Deckelbaum's family name was incorrect and Miliard Derbew's and Jamie Morgan's given names were incorrect. The names are correct as reflected in this erratum. The original article has also been updated.

The online version of the original article can be found under doi:10.1007/s00268-017-4028-1.

Fizan Abdullah

fabdullah@luriechildrens.org

Department of Surgery, Brigham and Women's Hospital, Boston, MA, USA
Center for Surgery and Public Health, Brigham and Women's Hospital, Boston, MA, USA

Division of Pediatric Surgery, Department of Surgery, Ann \& Robert H. Lurie Children's Hospital of Chicago, 225 East Chicago Ave, Box 63, Chicago, IL 60611, USA 
4 The Global Alliance for Surgical, Obstetric, Trauma, and Anaesthesia Care, New York, NY, USA

5 Selfless, London, UK

6 ReSurge International, Sunnyvale, CA, USA

7 The Pan African Association of Surgeons, Parktown, Johannesburg, South Africa

8 Department of Surgery, Mayo Clinic Florida, Jacksonville, FL, USA

9 Society of American Gastrointestinal and Endoscopic Surgeons, Los Angeles, CA, USA

10 St. Paul Medical College, Addis Ababa, Ethiopia

11 Jhpiego, An Affiliate of Johns Hopkins University Baltimore, Baltimore, MD, USA

12 African Agency for Integrated Development, Kampala, Uganda

13 Operation Smile, Virginia Beach, VA, USA

14 Alliance for Surgery and Anaesthesia Presence, Lupsingen, Switzerland

15 FIA Foundation, London, UK

16 AIC Kijabe Hospital, Kijabe County, Kenya

17 Netherlands Society for International Surgery, Amsterdam, The Netherlands

18 Global Pediatric Surgery Network, Portland, OR, USA

19 American Board of Surgery, Philadelphia, PA, USA

20 Rotaplast International, San Francisco, CA, USA

21 Primary Trauma Care Foundation, Oxford, UK

22 Johns Hopkins School of Public Health, Baltimore, MD, USA

23 International Collaboration for Essential Surgery, Angwin, CA, USA

24 Centre for Global Surgery, Montreal, QC, Canada

25 McGill University Health Centre, Montreal, QC, Canada

26 The College of Surgeons of East, Central and Southern Africa, Arusha, Tanzania

27 University of Utah Center for Global Surgery, Salt Lake City, UT, USA
39 American Association of Nurse Anesthetists, Park Ridge, IL, USA

\section{Care, Geneva, Switzerland}

46 Tropical Health and Education Trust, London, UK

47 Roads for Life, Beirut, Lebanon

\section{Switzerland}

52 Department of Anesthesiology and Critical Care Medicine, Johns Hopkins University, Baltimore, MD, USA

53 American College of Obstetricians and Gynecologists, Washington, DC, USA

54 Institute of Preventive Medicine, Environmental and Occupational Health - Prolepsis, Attica, Greece

55 National and Kapodistrian University, Athens Medical School, Athens, Greece

56 Mercy Ships, Lindale, TX, USA

57 Kenya Society of Anaesthesiologists, Nairobi, Kenya

58 Royal College of Surgeons of Ireland, Dublin, Ireland

59 Permanent Mission of the Republic of Zambia to the United Nations, Geneva, Switzerland

60 Mount Sinai Health System, New York, NY, USA

61 AO Alliance Foundation, Davos, Switzerland

62 Vanderbilt University Medical Center, Nashville, TN, USA

63 Physicians for Peace, Norfolk, VA, USA

64 Solidarity Bridge, Evanston, IL, USA

65 Diamedica UK Ltd, Devon, UK

66 University of Tennessee Health Science Center, Memphis, TN, USA

67 William Novick Global Cardiac Alliance, Memphis, TN, USA

68 West African College of Surgeons, Lagos, Nigeria

69 Nigerian Society of Anesthetists, Lagos, Nigeria

70 Organization of American States, Washington, DC, USA

71 American Society of Anesthesiologists, Schaumburg, IL, USA

72 The Institute of Global Health Innovation, Imperial College London, London, UK

73 Korle-Bu Neuroscience Foundation, Langley, BC, Canada 
74 Assist International, Scotts Valley, CA, USA

75 International Association of Oral and Maxillofacial Surgeons, Chicago, IL, USA

76 International Federation of Nurse Anesthetists, Sursee, Switzerland

77 Indus Hospital Pakistan, Karachi, Pakistan

78 Global Surgery Initiative, Johns Hopkins University, Baltimore, MD, USA

79 Mending Kids, Burbank, CA, USA

80 World Federation of Associations of Pediatric Surgeons, Geneva, Switzerland

81 Pan African Academy of Christian Surgeons, Linden, NC, USA
82 Smile Train, New York, NY, USA

83 Association for Academic Surgery, Los Angeles, CA, USA

84 GE Foundation, Chicago, IL, USA

85 AmeriCares, Stamford, CT, USA

86 Global ENT Outreach, Coupeville, WA, USA

87 CURE International, Lemoyne, PA, USA

88 HEAL Africa, Gisengyi, Rwanda

89 Plasticos Foundation, Newport Beach, CA, USA

90 IVUmed, Salt Lake City, UT, USA

91 2nd Chance Association Reconstructive Surgery for Life Reconstruction, Meyrin, Switzerland 